\title{
Coffin-Siris syndrome
}

INSERM

\section{Source}

INSERM. (1999). Orphanet: an online rare disease and orphan drug data base. Coffin-Siris syndrome. ORPHA:1465

Coffin-Siris syndrome (CSS) is a rare congenital multi-systemic genetic disorder characterized by aplasia or hypoplasia of the distal phalanx or nail of the fifth digit, developmental delay, intellectual disability, coarse facial features, and other variable clinical manifestations. 